\title{
Ação dos flavonóides na cicatrização por segunda intenção em feridas limpas induzidas cirurgicamente em ratos Wistar
}

\section{Flavonoid action in second intention healing in surgically-induced clean wounds in Wistar rats}

\author{
Alno Poiares Vieira ${ }^{1}$; Nádia Rosa dos Santos ${ }^{1}$; José Henrique Saraiva Borges ${ }^{2}$; \\ Mariana Pinheiro Alves Vincenzi ${ }^{3}$; Wanderlei Onofre Schmitz ${ }^{4}$
}

\section{Resumo}

Os flavonóides representam um dos principais grupos de substâncias com atividades farmacológicas em plantas, e são utilizados para elevar a eficácia do processo de cicatrização em feridas e úlceras. A própolis e o chá verde (Camellia sinensis) são dois produtos ricos em flavonóides que apresentam indicações como antiinflamatórios, antibacterianos, antioxidantes e cicatrizantes. $O$ presente estudo tem por objetivo avaliar a ação da própolis e do chá verde no processo de cicatrização em feridas limpas. As feridas foram produzidas em 20 ratos Wistar, e em cada rato, foram induzidas duas lesões simétricas de $11 \mathrm{~mm}$ de diâmetro, utilizando-se um Punch cirúrgico. As lesões se localizavam do lado esquerdo e direito da região torácica lateral. Posteriormente, os ratos foram divididos em 2 grupos. Grupo 1 - grupo tratado com soro fisiológico à $0,9 \%$ (lateral esquerda) e com creme a base de chá verde (Camellia sinensis) à 20\% (lateral direita); Grupo 2 - grupo tratado com creme base (lateral esquerda) e tratados com creme a base de própolis à $20 \%$ (lateral direita). Os diâmetros das lesões foram medidos a cada três dias. A cicatrização das lesões ocorreu em 15 dias, sendo que não houve diferença significativa entre os tratamentos, apesar dos grupos tratados com creme de chá verde e de própolis apresentaram melhor evolução durante o tratamento.

Palavras-chave: Cicatrização. Ratos. Flavonóides. Camellia sinensis. Chá verde. Própolis.

\begin{abstract}
Flavonoids represent one of the main groups of substances with pharmacological activities in plants. They are used to increase the effectiveness of the healing process in wounds and ulcers. Propolis and green tea (Camellia sinensis) are two products rich in flavonoids that present indications as: antiinflammatory, antibacterial, antioxidant and healing ones. The present study aims to evaluate the action of propolis and green tea on the healing process in clean wounds. The wounds were produced in 20 Wistar rats. In each rat two symmetrical lesions of $11 \mathrm{~mm}$ diameter were induced using a surgical punch. The lesions were located on the left and right sides of the lateral thoracic region. Later the rats were divided in 2 groups. Group 1 - treated with $0.9 \%$ physiologic solution (left side), and with green teabased cream (Camellia sinensis) at 20\% (right side); Group 2 - treated with base cream (left side) and treated with propolis-based cream at $20 \%$ (right side). The lesions diameters were measured every three
\end{abstract}

1 Acadêmicos do curso de Farmácia do Centro Universitário da Grande Dourados-Unigran/MS.

2 Prof. Msc. Em Cirurgia Veterinária pela Universidade de São Paulo-SP. Professor de Clínica Cirúrgica do Centro Universitário da Grande Dourados - Unigran/MS.

3 Profa. Msc. Coordenadora do Hospital Veterinário do Centro Universitário da Grande Dourados - Unigran/MS.

4 Prof. Msc. em Patologia Experimental pela Universidade Estadual de Londrina-PR. Professor de Patologia no Centro Universitário da Grande Dourados - Unigran/MS. E-mail-wandererita@ig.com.br.

Semina: Ciências Biológicas e da Saúde, Londrina, v. 29, n. 1, p. 65-74, jan./jun. 2008 
days. The lesions healing was observed after 15 days, and there was no significant difference among the treatments, despite groups treated with green tea and propolis cream presenting better evolution during the treatment.

Keywords: Healing. Rats. Flavonoids. Camellia sinensis. Green tea. Propolis.

\section{Introdução}

Os flavonóides representam um dos grupos fenólicos mais importantes e diversificados entre os produtos de origem vegetal, sendo amplamente distribuídos em frutas, vegetais, sementes, flores e cascas de árvores e vários destes alimentos são parte integrante da dieta humana (COOK; SAMMAN, 1996). Os flavonóides são os principais compostos com atividade farmacológica encontrados na própolis e no chá verde(Camelliasinensis). Quando ingeridos, os flavonóides interferem em alguns processos fisiológicos do organismo, como a absorção de ferro e de vitaminas, e estimulam a cicatrização. Ele agem como antioxidantes, combatendo os radicais livres, possuem atividade antimicrobiana e moduladora do sistema imune, apresentam ação antiinflamatória, analgésica, regenerativa de cartilagens, ossos e produzem vasodilatação (CHEN; ZANG; XIE, 2005; MENEZES, 2005; FERNANDES JUNIOR et al., 2006).

Os principais compostos químicos encontrados em amostras de própolis são os ácidos e ésteres alifáticos, os ácidos e ésteres aromáticos, os açucares, os álcoois, os aldeídos, os ácidos graxos, os aminoácidos, os esteróides, as cetonas, as charconas e as di-hidrocharconas, os flavonóides (flavonas, flavonóis e flavononas) e os terpenóides. A própolis possui grande variação em sua composição, e muitos compostos já foram isolados, mas, de forma geral, a própolis bruta, ou seja, a própolis recolhida de uma colméia de abelhas, apresenta em sua composição básica cerca de $50 \%$ a $60 \%$ de resinas e balsamo, $30 \%$ a $40 \%$ de ceras, $5 \%$ a $10 \%$ de óleos essenciais, $5 \%$ de grãos de pólen, além de microelementos, como alumínio, cálcio, ferro e pequenas quantidades de vitaminas (ANDREA; COSTA; CLARTON, 2005).

Já no chá verde, os índices de flavonóides são de aproximadamente $20 \%$ (peso seco) da folha do chá verde.Comosubstânciabiológicaativa, osflavonóides contribuem para muitas das características que fazem do chá verde um componente altamente valioso da dieta humana (PUNYASIRI et al., 2004). O chá verde contém proteínas (15 a 20\%), glicídeos (5\%), ácido ascórbico, vitaminas do complexo $\mathrm{B}$ e bases púricas, especialmente cafeína ( 2 a 4\%), polifenóis (30\%): monosídeos e flavionóis e flavonas, catecóis e epicatecóis livres e esterificados pelo ácido gálico e produtos de condensação e taninos (10 a 24\%). A principal classe de componentes bioativos são as catequinas e incluem a: epicatequina (EC), epigalocatequina (EGC), galato-3-epicatequina (ECG), galato-3-epigalocatequina (EGCG). As catequinas correspondem a aproximadamente $26,7 \%$ dos compostos derivados das folhas secas do chá verde, dos quais $11 \%$ são formados por EGCG, $10 \%$ de EGC, $2 \%$ de ECG, 2,5\% EC e $15 \%$ de polifenóis não identificados. (RICE-EVANS; MILLER; PAGANGA, 1996; MELLO; SANTOS apud SIMÕES et al., 2004).

A atividade farmacológica dos flavonóides se deve, principalmente às suas características estruturais, pois os flavonóides apresentam uma forma estrutural característica, o composto tricíclico. Estas propriedades estão relacionadas com a presença de radicais ligados aos seus anéis. A presença de grupos hidroxil na posição carbono 3 do anel $\mathbf{C}$, a presença de dupla ligação entre os carbonos 2 e 3 do anel $\mathbf{C}$ e o número de radicais hidroxil ligados nos anéis $\mathbf{A}$ e $\mathbf{B}$, aumentam sua atividade antioxidante (ZUANAZZI apud SIMÕES et al., 2004; COOK; SAMMAN, 1996).

Considerando as características e componentes do chá verde e da própolis, propusemos neste trabalho o estudar a ação cicatrizante destes compostos. 


\section{Materiais e métodos}

Animais de experimentação

Foram utilizados 20 ratos Wistar, machos, de idade adulta e com peso inicial de $180 \pm 20 \mathrm{~g}$. Os animais foram mantidos em gaiolas individuais de polietileno com tampa de aço inox, forradas com maravalha autoclavada, que foi trocada três vezes por semana. A temperatura ambiente foi mantida em torno de $20^{\circ} \mathrm{C}$ à $25^{\circ} \mathrm{C}$, a umidade relativa do ar e a quantidade de ruído foram mantidas em condições ideais. O fotoperíodo foi controlado para prover luz durante 12 horas diárias (6:00 às 18:00 horas). A alimentação foi feita uma vez ao dia com ração padrão para a espécie, autoclavada. A água potável foi fornecida ad libitum para os animais.

\section{Delineamento experimental}

Após uma semana de adaptação, os animais foram distribuídos aleatoriamente em gaiolas coletivas e divididos em 2 grupos: grupo 1, formado por animais tratados com soro fisiológico a $0,9 \%$ (lateral esquerda) e tratados com creme base incorporado com chá verde (Camellia sinensis) a 20\% (lateral direita); grupo 2, formado por animais tratados com creme base (lateral esquerda) e tratados com creme base incorporado própolis a 20\% (lateral direita). Os animais foram tratados até a cicatrização das feridas.

\section{Procedimento cirúrgico}

Para todos os procedimentos dolorosos e/ou situações de estresse, foi administrada a anestesia geral, feita por aplicação intra-muscular de $20 \mathrm{mg} /$ $\mathrm{Kg}$ de Cloridrato de Ketamina a $10 \%$, e $5 \mathrm{mg} / \mathrm{Kg}$ de Xilazina a $2 \%$. Antes da realização das lesões, foi realizada a tricotomia com auxílio de lâmina de barbear, logo após, foi feita a anti-sepsia do local com álcool 70\% para posterior produção da lesão. A ferida foi produzida com o auxilio de punch metálico de $11 \mathrm{~mm}$, com lâmina cortante na borda: retirou-se a pele e a tela subcutânea, e expôs-se a fáscia muscular dorsal. Para a indução das feridas, os animais foram mantidos em decúbito lateral direito para a lesão da região torácica lateral esquerda e em decúbito lateral esquerdo para a lesão da região torácica direita. Após a indução da lesão, deu-se imediatamente o início do tratamento.

\section{Tratamento das feridas}

As feridas foram tratadas diariamente, uma vez ao dia, até a cicatrização completa da lesão. A cada nova reposição da medicação, as feridas foram lavadas com solução fisiológica $0.9 \%$ para a remoção de crostas e resíduos do creme, e esses foram aplicados novamente com o auxilio de espátula plástica. As feridas foram mensuradas, com o auxílio de Paquímetro ACO Vernier Caliper a cada 3 dias.

\section{Preparo do creme de chá verde (Camellia sinensis)}

Foram manipulados $60 \mathrm{~g}$ do creme base contendo o chá verde na concentração de $20 \%$, com o uso da seguinte técnica: 1) foram pesados todos os componentes da fase oleosa (F1) do creme nas seguintes proporções: cera não iônica (cosmowax) (15.70\%), Óleo mineral (Vaselina Liquida) $(7.00 \%)$, Propilparabeno (Nipazol) (0.10\%) e BHT (0.07\%), em seguida foram aquecidos até $80^{\circ} \mathrm{C} ; 2$ ) foram pesados todos os componentes da fase aquosa (F2) nas seguintes proporções: Metilparabeno (Nipagim) $(0.20 \%)$, Propilenoglicol $(5.00 \%)$, EDTA $(0.14 \%)$ e Água Destilada q.s.p., em seguida a mistura também foi aquecida e seus componentes também foram aquecidos até $80^{\circ} \mathrm{C}$; 3 ) a $\mathrm{F} 2$ foi vertida sobre a F1, sendo em seguida agitado lentamente; 4) as fases foram homogeneizadas até o momento do resfriamento (aproximadamente $30^{\circ} \mathrm{C}$ ); 5) foram adicionados à mistura silicone volátil $(2.80 \%)$ e Germal a $50 \%(0.85 \%)$, e ela foi novamente homogeneizada; 6) o pH foi corrigido até 6.0. O chá verde foi incorporado ao creme-base na proporção 
de $20 \%$ após o procedimento descrito acima, e estava na forma de Tintura a $62 \%$ de Álcool, foi adquirida da Empresa Brasileira de Radiações LTDA EMBRARAD.

Preparo do creme de própolis

Foram manipulados $60 \mathrm{~g}$ do creme base contendo própolis na concentração de $20 \%$, por meio da seguinte técnica: 1) foram pesados todos os componentes da fase oleosa (F1) do creme nas seguintes proporções: cera não iônica (cosmowax) (15.70\%), óleo mineral (Vaselina Liquida) $(7.00 \%)$, propilparabeno (Nipazol) (0.10\%) e BHT (0.07\%), em seguida foram aquecidos até $80^{\circ} \mathrm{C}$;2) Foram pesados todos os componentes da fase aquosa (F2) nas seguintes proporções: metilparabeno (Nipagim) $(0.20 \%)$, propilenoglicol(5.00\%),\%), EDTA $(0.14 \%)$ e água destilada q.s.p., em seguida foram também aquecidos até $80^{\circ} \mathrm{C} ; 3$ ) a $\mathrm{F} 2$ foi vertida sobre a F1, e em seguida, agitou-se lentamente; 4) as fases foram homogeneizadas até o momento do resfriamento (aproximadamente $30^{\circ} \mathrm{C}$ ); 5) foram adicionados a mistura, silicone volátil $(2.80 \%)$ e germal a $50 \%(0.85 \%)$ e homogeneizou-se novamente a mistura; 6) o $\mathrm{pH}$ foi corrigido até 6.0. A própolis foi incorporada ao creme base na proporção de $20 \%$ após o procedimento descrito acima. A própolis que foi incorporada ao creme base estava na forma de Tintura de Própolis a 65\% de Álcool ou Polialcoois, foi adquirido da empresa "DEG - Importação de Produtos Químicos LTDA".

\section{Análise estatística}

Para a avaliação dos diferentes grupos experimentais, foi utilizada a Análise de Variância (ANOVA), e para comparação entre as médias foi utilizado o teste de Tukey. Foram considerados como estatisticamente significativos os valores de $\mathrm{p}<0,05$.

\section{Resultados e discussão}

A tabela 1 apresenta os valores de peso e área da lesão dos animais durante o tratamento dos grupos. Podemos observar que os diâmetros médios das lesões iniciais são muito próximos, indicando uma uniformidade aos grupos: soro fisiológico à $0,9 \%$ $(12,75 \pm 0,75)$, com creme-base $(13,60 \pm 0,37)$, creme com chá verde $20 \%(13,00 \pm 0,47)$ e com creme própolis $20 \%(13,5 \pm 0,18)$.

Tabela 1. Acompanhamento das lesões dos animais que receberam tratamento diário com soro fisiológico à $0,9 \%$, creme base, creme com chá verde $20 \%$ e com creme própolis $20 \%$.

\begin{tabular}{cccccc}
\hline Ratos n=10 & & \multicolumn{4}{c}{ Diâmetro da Lesão (mm) } \\
\hline $\begin{array}{c}\text { Dias de } \\
\text { Avaliação }\end{array}$ & Peso (g) & $\begin{array}{c}\text { Solução Fisiológica } \\
\mathbf{0 , 9 \%}\end{array}$ & Creme Base & $\begin{array}{c}\text { Chá Verde } \\
\mathbf{2 0 \%}\end{array}$ & $\begin{array}{c}\text { Própolis } \\
\mathbf{2 0 \%}\end{array}$ \\
\hline $\mathbf{0}$ & $197,93 \pm 3,78$ & $12,75 \pm 0,75$ & $13,60 \pm 0,37$ & $13,00 \pm 0,47$ & $13,5 \pm 0,18$ \\
$\mathbf{3}$ & $196,44 \pm 2,87$ & $10,29 \pm 0,79$ & $11,33 \pm 0,44$ & $10,77 \pm 0,57$ & $10,7 \pm 0,26$ \\
$\mathbf{6}$ & $190,56 \pm 2,93$ & $7,83 \pm 0,83$ & $9,06 \pm 0,51$ & $8,56 \pm 0,67$ & $7,89 \pm 0,35$ \\
$\mathbf{9}$ & $183,00 \pm 3,77$ & $4,22 \pm 0,69$ & $4,78 \pm 0,53$ & $4,44 \pm 0,34$ & $3,44 \pm 0,57$ \\
$\mathbf{1 2}$ & $145,00 \pm 2,16$ & $0,29 \pm 0,29$ & $1,00 \pm 0,49$ & $0,29 \pm 0,29$ & $0,86 \pm 0,46$ \\
$\mathbf{1 5}$ & $193,57 \pm 4,01$ & $0,0 \pm 0,0$ & $0,0 \pm 0,0$ & $0,0 \pm 0,0$ & $0,0 \pm 0,0$ \\
\hline
\end{tabular}

( 10 ) = número de ratos por grupo analisados; Médias \pm erro padrão. 
Os diâmetros da lesão encontrados nos ratos tratados com a própolis a $20 \%$ durante o tratamento, são inferiores aos diâmetros das lesões tratadas com chá verde e das lesões tratadas apenas com o creme-base e, apesar das diferenças não serem estatisticamente significativas, o creme a base de própolis se mostrou relativamente mais eficiente durante o tratamento. Outro dado que se mostra interessante é que as lesões tratadas com solução fisiológica a $0,9 \%$, cicatrizaram na mesma proporção das lesões tratados com medicamentos, indicando que manter a ferida limpa já é um grande avanço no processo de cicatrização. Nossos dados foram diferentes dos resultados encontrados por Rahal et al. (2003), que realizou um estudo em feridas limpas com 60 ratos Wistar tratando-os com pomada de própolis durante 21 dias. Os resultados do estudo de Rahal et al. (2003) mostram uma maior diminuição nas lesões tratadas com própolis em relação as lesões tratadas com solução fisiológica a $0,9 \%$. O tratamento realizado por Rahal et al. apresentou total reepitelização no $14^{\circ}$ dia do experimento, estes dados corroboram o nosso experimento onde as lesões estavam cicatrizadas no $15^{\circ}$ dia do experimento. Também não podemos confirmar os estudos de Pajonk et al. (2006) que afirmam que o extrato do chá verde induziu uma melhor reconstituição da pele em pacientes que sofreram de toxicidade na pele causada pela radioterapia e que o extrato de chá verde é uma opção eficiente para o tratamento destes pacientes.

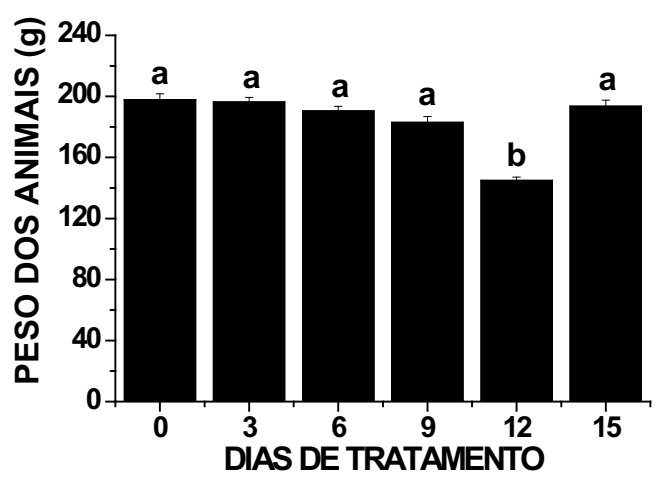

Gráfico 1. Peso médio dos animais durante os tratamentos. Médias \pm erro-padrão. Os grupos marcados com a mesma letra são semelhantes entre si (Teste de Tukey).
Podemos observar que o peso dos animais diminuiu à medida que era feito o tratamento (gráfico 1), e a diferença pode estar relacionada à dificuldade de movimentação dos animais , devido as lesões na região toráxica, que impediam o acesso destes animais a ração. A diferença também pode estar associada com o processo inflamatório, que produz citocinas inflamatórias e Fator de Necrose Tumoral (FNT) que agem como mediadores da inflamação e da imunidade. Além disso, níveis séricos elevados de FNT causam a perda de peso devido a estimulação do aumento dos níveis séricos de leptina, pelo FNT. A leptina é uma proteína relacionada com a sensação de saciedade, níveis aumentados desta proteína induzem o organismo ao gasto energético e a uma diminuição no consumo de alimento, causando falta de apetite e perda de peso (PASCHOALINI et al., 2005; NERY et al., 2006). Essas possibilidades são confirmadas pelo gráfico: nele se demonstra que o menor peso médio dos animais foi no $12^{\circ}$ de tratamento $(145,00 \pm 2,61)$ e já no $15^{\circ}$ de tratamento quando a cicatrização já estava completa, o peso dos animais voltou a subir $(193,00 \pm 4,01)$. Esse fato indica o fim do processo inflamatório e cicatricial.

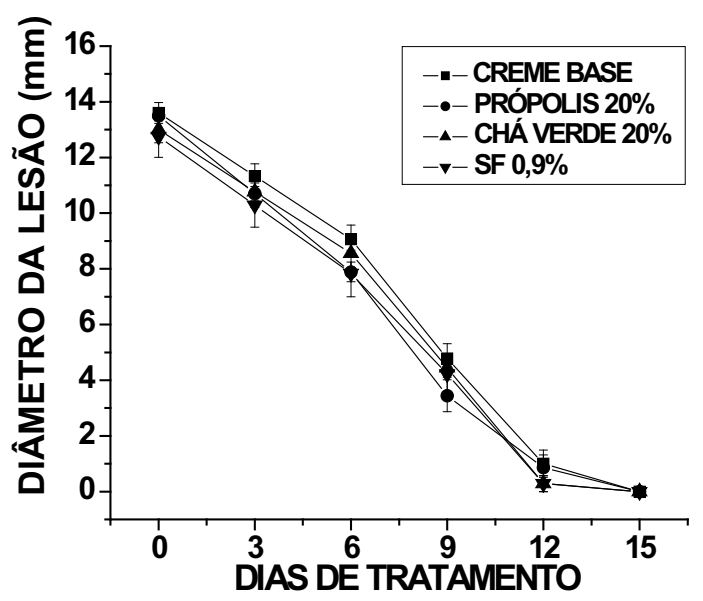

Gráfico 2. Comparação entre os tratamentos dos grupos: soro fisiológico à $0,9 \%$, creme base, creme com chá verde $20 \%$ e creme com própolis $20 \%$. Médias \pm erro-padrão.

O gráfico 2, ao correlacionar todos os tratamentos, permite verificar que os ratos não 
apresentaram uma diferença significativa entre os valores do diâmetro das lesões, pois as características observadas nas lesões também eram semelhantes. As lesões observadas (Figura 1 e 2) no primeiro dia do experimento, após a hemóstase da lesão, apresentavam bordas bem definidas, não apresentando sinais de inflamação, mas apenas um pequeno edema. A ferida inicial por se tratar de uma ferida limpa, não apresentava tecido necrótico e era ideal para a observação inicial da lesão. No $3^{\circ}$ dia do tratamento, as lesões já apresentavam grandes sinais de melhora, com cicatrização parcial das lesões, mas ainda havia edema e sinais de infamação. No sexto dia, já se pode observar na lesão a formação de tecido de granulação nas lesões, com redução do edema, mostrando nítida melhora do quadro. No nono dia de tratamento, a ferida já se mostra com acentuada formação de tecido de granulação e bem contraída, e progrediu para a reepitelização. No décimosegundo dia, a ferida se encontra bem contraída e quase totalmente reepitelizada e no décimo-quinto dia, encontrava-se totalmente reepitelizada.

Durante o tratamento das lesões, apesar de não ter havido diferença significativa entre os grupos, pôde-se observar algumas diferenças na evolução das lesões nos diferentes tipos de tratamento, por exemplo: sangramentos, inícios de infecção e aderência, só foram observados em lesões tratadas com solução fisiológica $0,9 \%$ e creme base sem princípios ativos. Portanto as lesões tratadas com própolis e chá verde (Figura 1 e 2) evoluíram melhor durante o tratamento, e não apresentaram sangramentos, infecções secundárias e tecido necrótico durante o tratamento. 

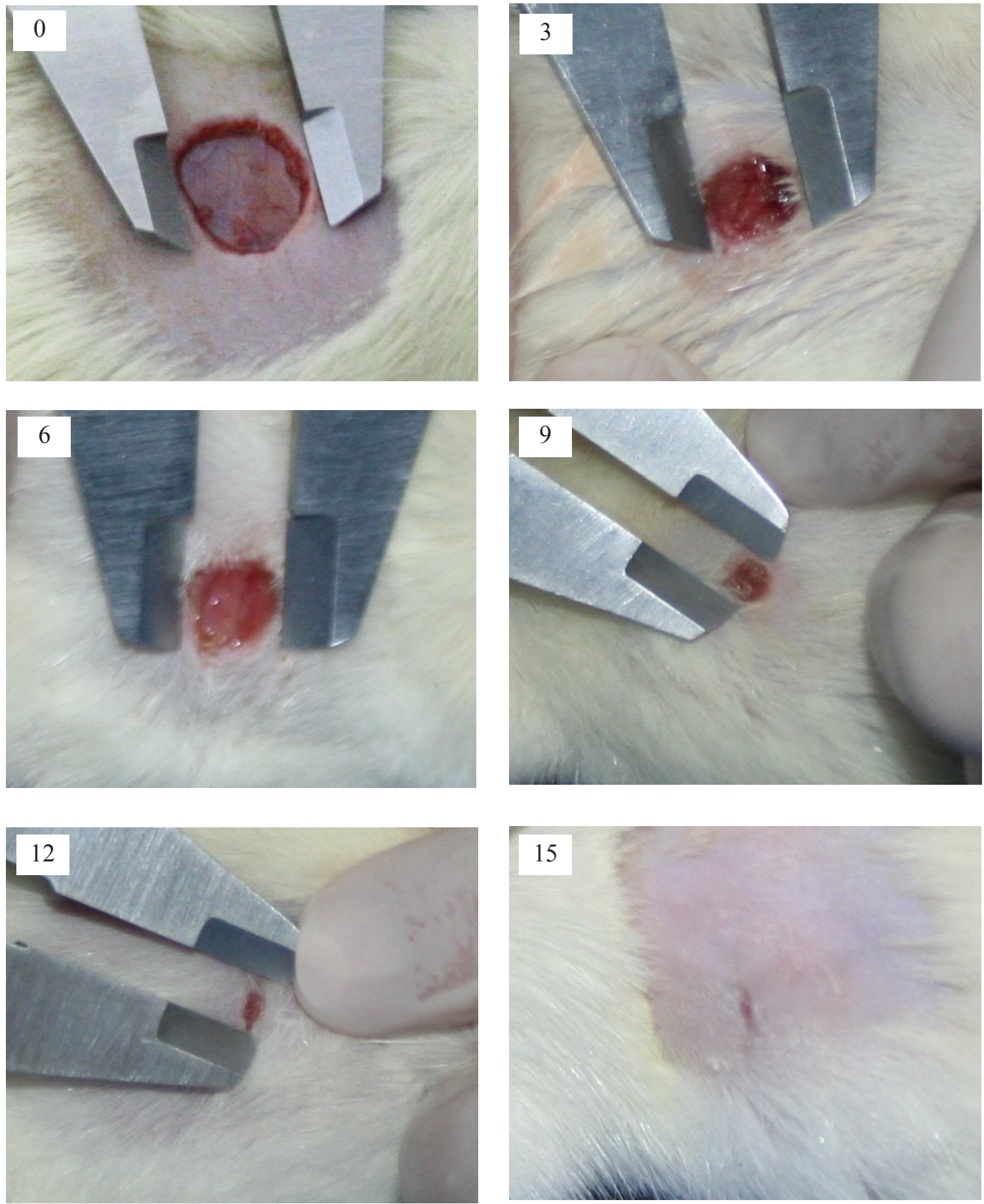

Figura 1. Acompanhamento das lesões durante o tratamento com um creme a base de própolis $20 \%$. As imagens acima de 0 a 15 representam as lesões a partir da primeira medida no início do tratamento (figura 0 ) até o fim do tratamento (figura 15). As fotografias foram obtidas a cada 3 dias, totalizando 15 dias de tratamento. 

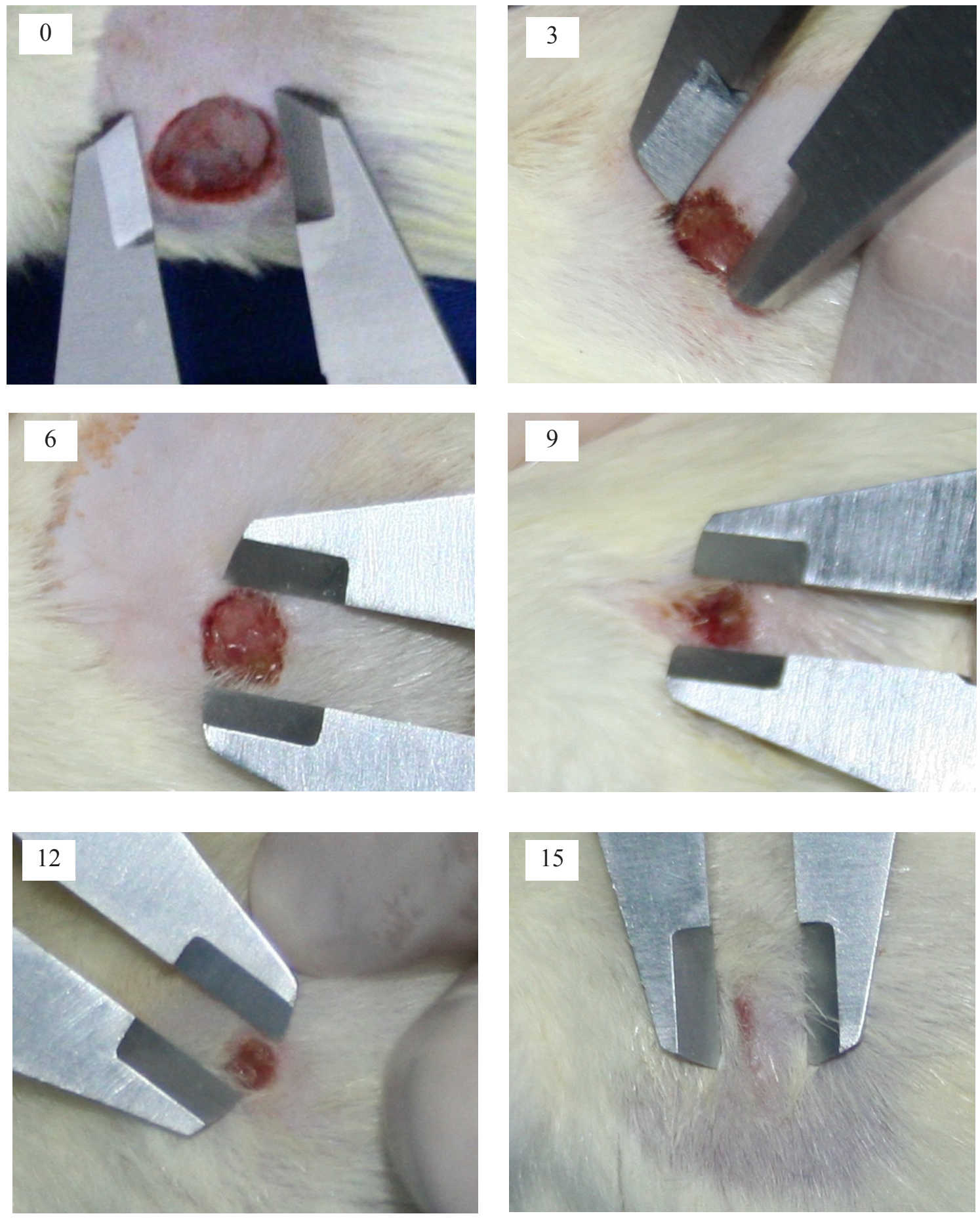

Figura 2. Acompanhamento das lesões durante o tratamento com um creme á base de chá verde $20 \%$. As imagens acima de 0 a 15 representam as lesões a partir da primeira medida no início do tratamento (figura 0 ), até o fim do tratamento (figura 15). As fotografias foram obtidas a cada 3 dias, totalizando 15 dias de tratamento. 


\section{Considerações finais}

Os resultados apresentados neste experimento de cicatrização com creme de chá verde e própolis a $20 \%$, não foram melhores que os tratamentos a base de solução fisiológica e creme base, comparando os tratamentos não houve diferença nos processos de cicatrização nos animais, apesar dos animais tratados com chá verde e própolis evoluírem melhor durante o tratamento. Para confirmar ou não a ação cicatricial dos flavonóides, são necessários novos estudos a respeito das ações farmacológicas dos flavonóides e estudos de dose/efeito, para que a população esteja cada vez melhor informada e possa fazer uso de produtos naturais com mais segurança e eficácia.

\section{Referências}

ANDREA, M. V.; COSTA, C. N.; CLARTON, L. Própolis na cura e prevenção de doenças? pode ser uma boa alternativa! Bahia agrícola, Manhuaçu, v. 7, n. 1, p. 19-21, set. 2005.

CHEN, H.; ZHANG, M.; XIE, B. Components and antioxidant activity of polysaccharide conjugate from green tea. Food Chemistry, Londres, v. 90, n. 1-2, p. 1721, 2005.

COOK, N. C.; SAMMAN, S. Flavonoids-Chemistry, metabolism, cardioprotective effects, and dietary sources. Journal of Nutritional Biochemistry, Stoneham, v. 7, n. 2, p. 66-76, Sep. 1996.

FERNANDES JUNIOR, A.; LOPES, M. M. R.; COLOMBARI, V.; MONTEIRO, A. C. M.; VIEIRA, E. P. Atividade antimicrobiana de própolis de Apis mellifera obtidas em três regiões do Brasil. Ciência rural, Santa Maria, v. 36, n. 1, p. 294-297, jan./fev., 2006.

MENEZES, H. Própolis: uma revisão dos recentes estudos de suas propriedades farmacológicas. Arquivos do Instituto Biológico, São Paulo, v. 72, n. 3, p. 405-411, jul./set., 2005.

NERY, J. A. C.; SALES, A. M.; ILLARRAMENDI, X.; DUPPRE, N. C.; JARDIM, M. R.; MACHADO, A. M. Contribuição ao diagnostico e manejo dos estados reacionais: uma abordagem prática. Anais Brasileiros de Dermatologia, Rio de Janeiro, v. 81, n. 4, p. 367-375, 2006.

PAJONK, F.; RIEDISSER, A.; HENKE, M.; McBRIDE, W.; FIEBICH, B. The effects of tea extracts on proinflammatory signaling. BioMed Central Medicine, London, v. 4, n. 28, p. 1-12., Dec. 2006.

PASCHOALINI, M. A.; RASCHCOWETZKI, A. M.; PEREIRA, I. S.; NOBRE, J. Q. C.; MARQUES, L. B.; SILVA, T. Regulação do peso corporal. In: SEMINÁRIOS DE INTERAÇÃO SOBRE OS ASPECTOS MORFOFUNCIONAIS ORAIS DE CLINICA MEDICA E DE SAÚDE PUBLICA, Santa Catarina, 2005. Santa Catarina: Universidade Federal de Santa Catarina, 2005.

PUNYASIRI, P. A. N.; ABEYSINGHE, I. S. B.; KUMAR, V.; TREUTTER, D.; DUY, D.; GOSCH, C.; MARETNS, S.; FORKMANN, G.; FISCHER, T. C. Flavonoid biosynthesis in the tea plant Camellia sinensis: properties of enzymes of the prominente epicatechin and catechin pathways. Archives of Biochemistry and Biophysics, New York, v. 431, n. 1, p. 22-30, 2004.

RAHAL S. C. et al. Utilização de própolis ou mel no tratamento de feridas limpas induzidas em ratos. Archives of Veterinary Science, Curitiba, v. 8, n. 1, p. 6167, 2003.

RICE-EVANS, C. A.; MILLER, N. J.; PAGANGA, G. Structure-antioxidant activity relationships of flavonoids and phenolic acids. Free Radical Biology \& Medicine, New York, v. 20, n. 7, p. 933-56, 1996.

SIMÕES, C. M. O.; SCHENKEL, E. P.; GOSMANN, G.; MELLO, J. C. P.; MENTZ, L. A.; PETROVICK, P. R. Farmacognosia: da planta ao medicamento. 5.ed. Porto Alegre/Florianópolis: UFRGS/UFSC, 2004. 
